\title{
VISUAL AND ACOUSTICAL SOCIAL DISPLAYS BY THE GRASSHOPPER ARPHIA CONSPERSA (ORTHOPTERA: ACRIDIDAE) ${ }^{1,2}$
}

\author{
By Robert B. Willey and Ruth L. Willey ${ }^{3}$
}

Many species of the Oedipodinae (band-wing grasshoppers) exhibit strikingly diverse social interactions invoking visual and acoustical communication between the sexes and between individuals of the same sex (Otte, I968, 1969).

The present paper is an account of the communication system of Arphia conspersa and will serve as an introduction to quantitative and experimental analyses of specific aspects of the behavior of this and other species.

\section{LIFE HISTORY}

Arphia conspersa is widespread throughout the western Great Plains from northern Mexico to the southern provinces of Canada and is found up to II,OOO feet elevation in the Rocky Mountains of southern Colorado where this study was made. We have found that these populations typically overwinter as nymphs and the eggs usually need a cold period to break diapause, implying a two-year life cycle. In the mountain areas near Gunnison, Colorado, adults have emerged consistently (I962-I968) four to five weeks after the snow has melted (June to July). The peak of abundance occurs about two weeks after the first observed emergence and the population dies out about three weeks later in most localities (Willey and Willey, 1967). In the vicinity of Boulder, however, a few adults may be found at all months of the year, even in open areas during warm days of the winter (Halliburton \& Alexander, 1964).

At higher elevations such as at Gothic (9,500 feet, Gunnison Co.) and Black Mesa (9,700 feet, Montrose-Gunnison Cos.) adults pass through most of their life without coming into contact with adults

\footnotetext{
${ }^{1}$ Research conducted at the Rocky Mountain Biological Laboratory, Crested Butte, Colorado; The University of Illinois at Chicago Circle; National Center for Atmospheric Research, Boulder, Colorado; and Ripon College, Wisconsin.

${ }^{2}$ This study was supported in part by grant GB-2201 from the National Science Foundation, three grants from the Graduate Research Board of the University of Illinois, and Sigma Xi-RESA Grants-in-Aid of Research for the summers of 1963 and 1968.

${ }^{3}$ Address of the co-authors: Department of Biological Sciences, University of Illinois at Chicago Circle, Box 4348, Chicago, Illinois 60680.
} 
of other related species, except for sparse populations of Aeropedellus clavatus (Acridinae). At lower elevations, Xanthippus corallipes, another oedipodine, is commonly sympatric with $A$. conspersa. The densest populations so far observed occur in short grass prairie parks near Los Pinos Pass ( Io,200 feet, Saquache Co.), Black Mesa, and Table Mesa (6,200 feet, Boulder Co.). We have counted as many as 60 males per acre, but usually the population averages fewer than 20 per acre with more or less clumped distribution. These densities would seem to be relatively low for efficiency of location of mates and may be correlated with the highly evolved signals for social communication described below.

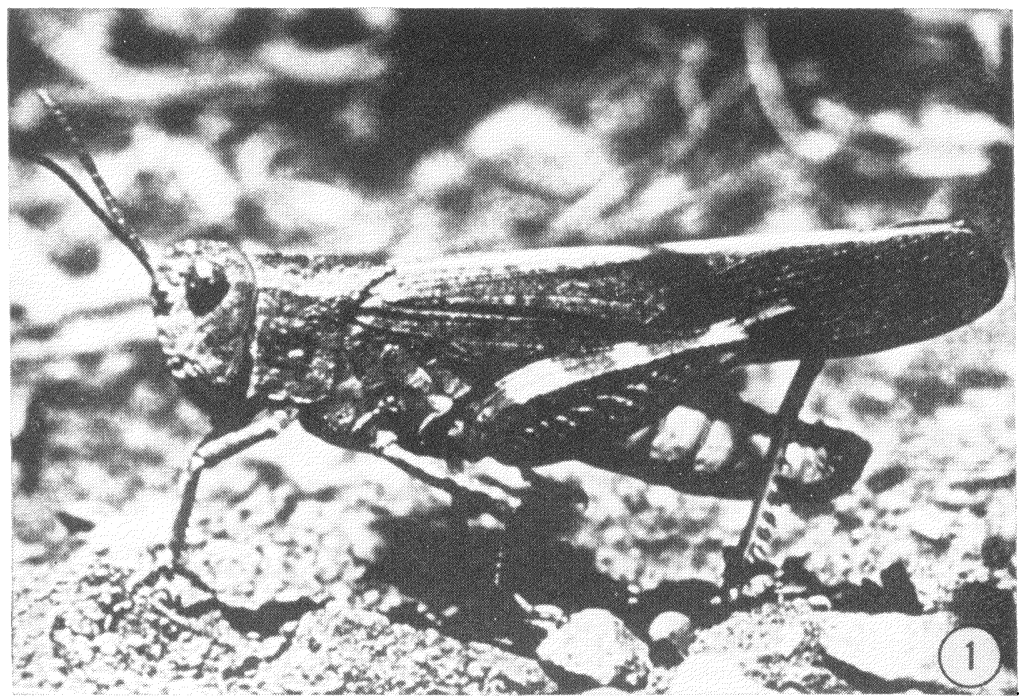

Figure 1. Male $A$. conspersa in alert pose, Table Mesa, Boulder Co. This male also was buzzing with the right hind leg (visible as 2 faint diagonal streaks).

\section{MATERIALS AND METHODS}

Field observations entailed sitting or standing quietly in the center of a population cluster. The members of this species are unwary enough to behave normally within a few inches of the observer. Completion of behavioral sequences have been observed on our nets, clothing and boots. Notetaking and scoring an outline sheet did not disturb the grasshoppers. Climatic conditions were noted; in a few 
experiments temperature and wind speed were measured with recording equipment. This study is still in progress. Most observations were made of Gothic, Black Mesa, Table Mesa and Los Pinos Pass populations from 196I to the present

Observations were also made on wild-caught and reared grasshoppers kept in a variety of cages. The most successful cage consisted of a simple plastic plant tray $8 " \times 12$ " filled with sand with wire screening over the top to form a "quonset". Two removable solid wooden semi-circles formed the ends. Young shoots of blue grass, rye grass, and dandelions were provided for food during the seasons when wild grasses were unavailable. A 6o or Ioow bulb provided heat and light which attracted the grasshoppers into a closely interacting group.

Movements were recorded with a Camex $8 \mathrm{~mm}$. reflex camera run at 16 and 32 frames per second, while sounds were recorded with a Nagra III tape system and an AKG condenser microphone (C6o with B6o power supply) equipped with a 24 inch parabolic reflector (Torngren Co.) for field recording from distances over 2 feet. Recordings were made in the laboratory without the parabola and, recently, with a Sennheiser 804 condenser microphone. Frequency response was checked with the $4000 \mathrm{~Hz}$ calibration tone of the Nagra. The movie film was Kodachrome II and the audiotape was Scotch 138. The audiospectrograms were produced on a Kay Electric Co. Model 675 Missile Data-Reduction Spectrograph (Missilyzer). The overall sound range of each audiospectrogram illustrated in this report was calibrated at the time of transfer to the spectrographic paper with a calibrated precision sine-square wave generator (model E-3IO). We also cross-checked the recorded calibration tones of the Nagra and the generator. We measured the overall amplitude of the sounds directly from the insect with a model I55IC sound level meter (General Radio Co.). The behavioral vocabulary is derived from Willey \& Willey (1964), R. Alexander (1967), and Otte (1968).

\section{Solitary behavior}

\section{OBSERVATIONS}

Males tend to be more active than females. They wander over the ground for distances up to 6 feet in a random path more or less determined by the microtopography. The manner of walking in males is a spurt of several complete leg movement sequences sepa- 
rated from the next sequence by a fractional-second pause. This spurt-walk becomes accentuated by a rapid raising and lowering of both hind legs with an open femoro-tibial angle of about $30^{\circ}$. One or two such flicks may occur whenever both hind legs are not in contact with the ground. The male, when approaching a high point, such as a pebble or a stick, often crawls upon it and stands in a motionless "alert pose" as in Figure I. At this time the male is very responsive to any sudden movement or sound on the part of the observer. Usually the visible reaction to a disturbance is a slight crouch, lifting of the antennae to the vertical, closing of the femorotibial angle of the hind legs and lowering of the hind femora to the horizontal. The subsequent reaction is usually a leap and flight. If the male is allowed to recover from the initial disturbance, he slowly resumes the alert pose and periodically snaps the hind femora to the vertical in a flicking motion up and down, singly or together. Minor disturbances such as small insects coming too close or a grass blade touching him will cause such a flick. In fact, some flicks seem to be spontaneous during the alert pose.

\section{Social behavior}

Signals associated with social interaction are (I) spontaneous flights which are accompanied by a clicking sound (crepitation) produced by the wings, (2) simple soundless flicks of the hind legs ("femur-tipping", Otte, I968), (3) femoro-tegminal stridulations which generate chirps, rasps, buzzes and squeals; and (4) soundless movements observed during contact between two grasshoppers which include tapping with the prothoracic tarsus, palpating with the antennae, rapid stroking with the palpi, butting with the frons, mounting by the male and, of course, genital contact. The emphasis in this paper will be placed on those signals transmitted at a distance between two or more individuals.

A signal, by our definition, must have some reaction-potential in the organism perceiving it. Our operational definition for a visual or auditory communication signal is the production of a measurable motion and/or airborne acoustical vibration by one individual followed in another individual by an action unrelated to what the latter was doing and unlikely to have occurred in the absence of the stimulation. Chemical signals could not be recorded in the present study. Frequent sounds such as mandible clicks, wing buzzes, substrate tapping with the tarsi, and tibio-tegminal clicks have produced no observable response in this species, and will not be considered in detail. 


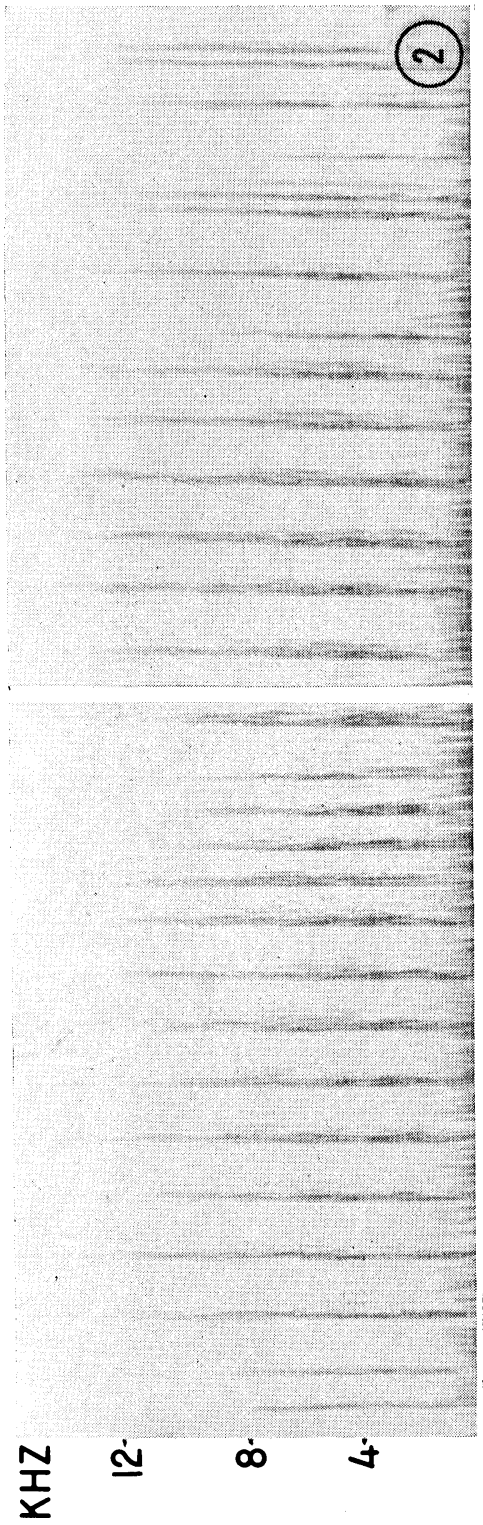

(5) 总

n

$\circ$

:to

$\stackrel{m}{\circ}$

N

0

$\overline{0}$

ㅇ $\dot{\infty} \dot{+}$ 


\section{The fight crepitation.}

The spontaneous aerial crepitation is a buzzing flight, which lasts one to three seconds, during which the grasshopper describes an arc one to ten feet in length and three feet in height. Males make more crepitation flights, by far, than females, which seldom are seen in flight except during the first weeks of the season. The flights by males may be repeated in a minute, but they average only one such sequence every three to four minutes at the peak of daily activity during the most active part of the short adult season. Even if disturbed, these insects usually crepitate normally. Only when disturbed a second time will they fly away relatively soundlessly. Crepitation flights are usually into the wind if there is only a slight breeze, although such flights are suppressed entirely by wind above Io m.p.h. On the other hand, silent escape flights are usually at least 30 feet in length and often extend over several hundred feet, flying with the wind (Willey \& Willey, 1967).

The sound produced by the wings during crepitation is shown in Figure 2. Each pulse is a broad spectrum click with no distinct fundamental frequency nor apparent harmonic. The highest amplitudes are in a range from 3000 to $8000 \mathrm{~Hz}$ and the total range of the sound is restricted by the effective frequency response of the recording system (20 to $\mathrm{I} 8,000 \mathrm{~Hz}$ ). To the human ear it is toneless and sharp. There are about 45 pulses per second and they are evenly spaced unless a change of direction or landing occurs. At these times the pulses take on an added component, appearing double, and are more closely spaced. These changes are probably due to the wings beating faster and out of phase with one another.

Male-female interaction (courtship and copulation).

The chirp is the primary sound generated by the male during courtship. This sound is produced by rubbing a ridge on the medial side of the hind femur on a linear series of pegs situated in both sexes on a modified intercalary vein of the tegmen. The chirp is a unitary sound probably produced by an intense pressure of the femur on the tegmen in a smooth up and down stroke cycle. As can be

Figure 2. Field recording of beginning and ending of flight crepitation. This flight began 3 feet from the microphone, described a long arc to 10 feet away and returned to the same spot. Note the increased pulse rate (= wing beat frequncy) as the insect gains altitude. The pulse rate in mid-flight is more regular. Also note the double wave fronts as the insect lands, probably representing wings beating out of phase with one another. The break in the middle of the display $=1.8$ seconds.

Figure 3. Audiospectrogram of Exakta camera re-set sounds. 


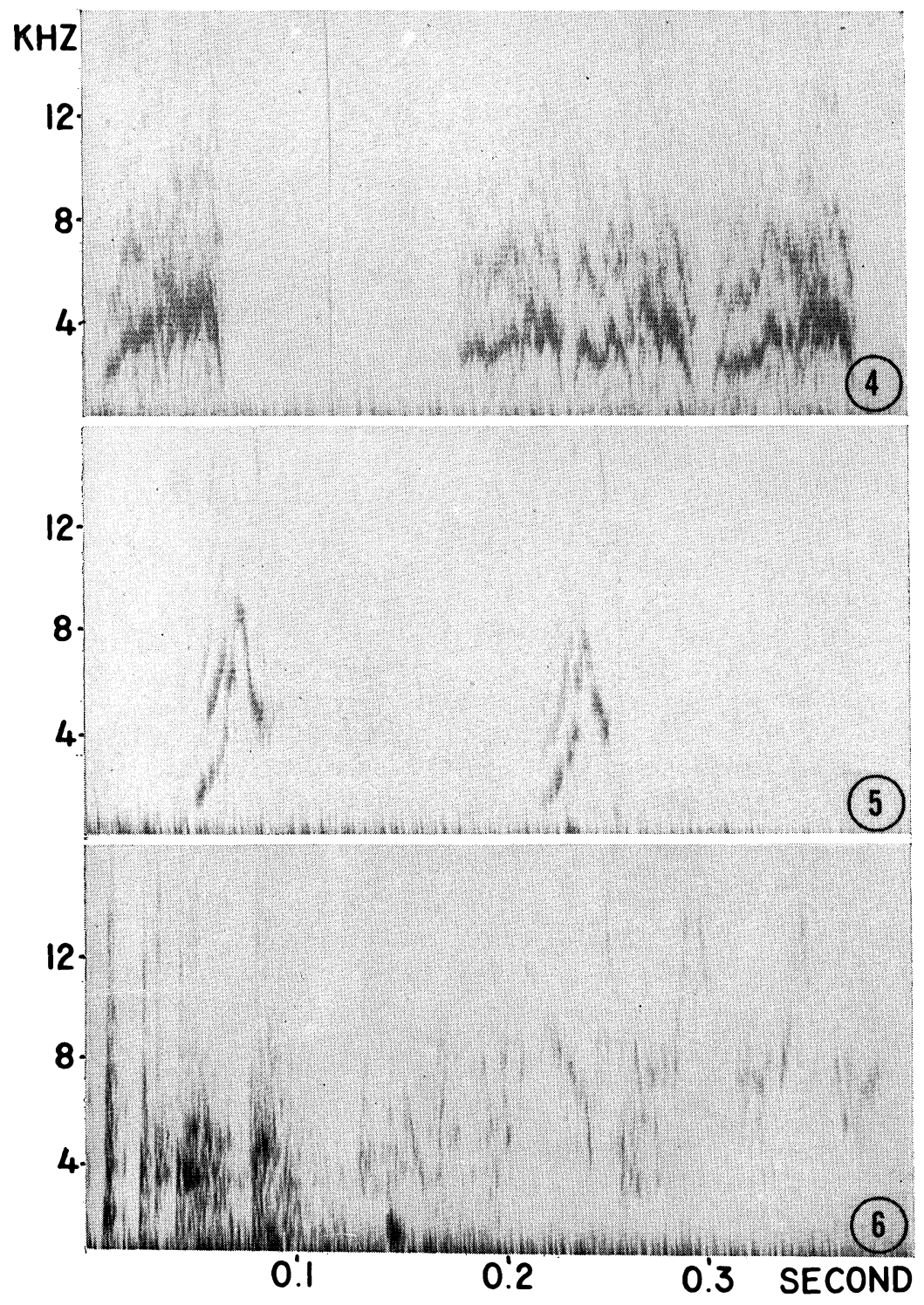


seen in Fig, 4, each chirp ranges to the limits of the recording apparatus but has an intense band about 500 cycles wide slurring upward and downward many times between 1500 and $5000 \mathrm{~Hz}$ with a duration of $40-80$ msec. Each slur is probably a small multiple acoustic effect of a short series of pegs on a resonating wing and the slurring effect probably is a function of pressure, velocity, and changing strike angle of the femoral ridge as it arcs along the pegs. Additional faint overtones are observed at 7000 to $9000 \mathrm{~Hz}$ and I 2000 to I $6000 \mathrm{~Hz}$. They are not likely to be heard by human ears and probably are an artifact of the spectrograph (Watkins, 1967). A sound between 3000 and $5000 \mathrm{~Hz}$ is usually picked up as approximating the tonal quality of the chirp. Chirps differ inter se in many ways and can be weak, strong, produced on the upstroke, downstroke, or both, high pitched, low pitched, etc. The average duration of a chirp is 60 msec and, when combined with other chirps in a phrase, has no standard interval. The sound intensity is difficult to measure directly, since the chirp is usually unitary and the

Figure 4. Laboratory recording of chirps; the multiple chirps were at the beginning of a courtship sequence in which the male attempted to mount immediately, was repulsed at first, followed the female for nearly a minute giving unitary chirps and finally mounted and successfully copulated. The similarity of the peaks in the major (= fundamental) frequency band indicated that this is a single movement by both legs, either up stroke or down stroke. The "ghost" harmonics every 3-5 KHz probably indicates a basic spike pulse modulated by the number of pulses (= teeth on the intercalary vein) struck per sec/given instant (Watkins, 1967), but this must be checked further. The unitary chirp and multiple chirps were selected separately and are not in any determined time relation to each other.

Figure 5. Audiospectrogram of chipmunk (Eutamias sp.) alarm cry. The fundamental frequency of this complex sound seems to be 1 to $8 \mathrm{KHz}$ which to human ears would average a high grasshopper chirp of $5 \mathrm{KHz}$. Since grasshoppers probably are tone deaf, the amplitude (at greater distance), great directionality of the sound, its duration, and spacing could be a good mimic of the chirp, thus causing the orientation of the two males described in the text.

Figure 6. Audiospectrogram of crepitation and squeal of two individuals in a caged population outdoors. The crepitation is separated from the squeal by two broad dark lines representing the landing of the insect on the wire netting. A smaller dark spot at about $1500 \mathrm{~Hz}$ represents a third impact on the wire. The squeal is difficult to reproduce clearly and is of much less amplitude than the crepitation and nearly the same as the background air noises. However, the great variation in carrier frequency shows the basic pattern. The 5 ascending major frequency peaks may represent multiple strokes, but at present we cannot ascertain how many strokes are produced nor what mechanism modulates the pulse rate frequency. 
needle of a sound level meter is not deflected fully by it. However, a strong chirp seems to peak at $50 \mathrm{db}$ at $4^{\prime \prime}$ on the $\mathrm{A}$ and $\mathrm{B}$ scales. [All readings use a reference level of o $\mathrm{db}=0.0002$ microbar, alt. $9500 \mathrm{ft}$., and the scales used are those recommended by Peterson and Gross (1963) for the given sound level and frequency.]

Males can usually detect a female as a female from at least two feet and spurt-run toward her emitting separated high intensity chirps as above. Figure 7 illustrates the general schema of courtship of receptive and non-receptive females. The female "signal" seems to be an inadvertent movement such as feeding, walking, grooming or no movement at all. Her greater size probably also is a sign stimulus. The male chirps vary from pulsed phrases of one to five chirps in succession. When he has approached within one inch of the female, he typically orients by facing her directly, frons to frons. The two grasshoppers "fence" mutually with their antennae and the male continues chirping. The male then moves to the female's side and faces her thorax. He may chirp and he may even butt his frons against the side of the thorax. The male finally places a prothoracic tarsus on her metathoracic femur, pats the substrate with his hind tarsi several times very rapidly and then attempts to mount from the rear of the female. Simultaneously, there often is a train of 4-5 chirps just before mounting.

Females seem to be sexually responsive as virgins io days after molt and again after laying the first egg pod. However, these data are derived from females that were group-isolated as nymphs until presentation of the males and it has been shown by Highnam \& Lusis (I962) that isolated females of Schistocerca gregaria mature more slowly. We considered a female receptive if copulation was completed. Some females actively solicited attention by males. After the short bout of antennal fencing initiated by mutual orientation and approach by both male and female, the female often turned while the male chirped, presented her side to the male, lowered the near hind leg and raised her opposite leg and both tegmina, exposing the whole abdomen. The valves of the ovipositor may open or at least move a bit. At this point three females of the total of 20 successful courtships observed fluttered the hind femoro-tibial joint against the ground but not high enough to contact the tegmen. After this the male gave his final burst of chirps and mounted. In one case, in which an old male of four weeks was involved, the female initially followed the male and patted his wing tip with a fore tarsus, while he ran away from her giving the male flutter-rasp (q.v.). Then he 

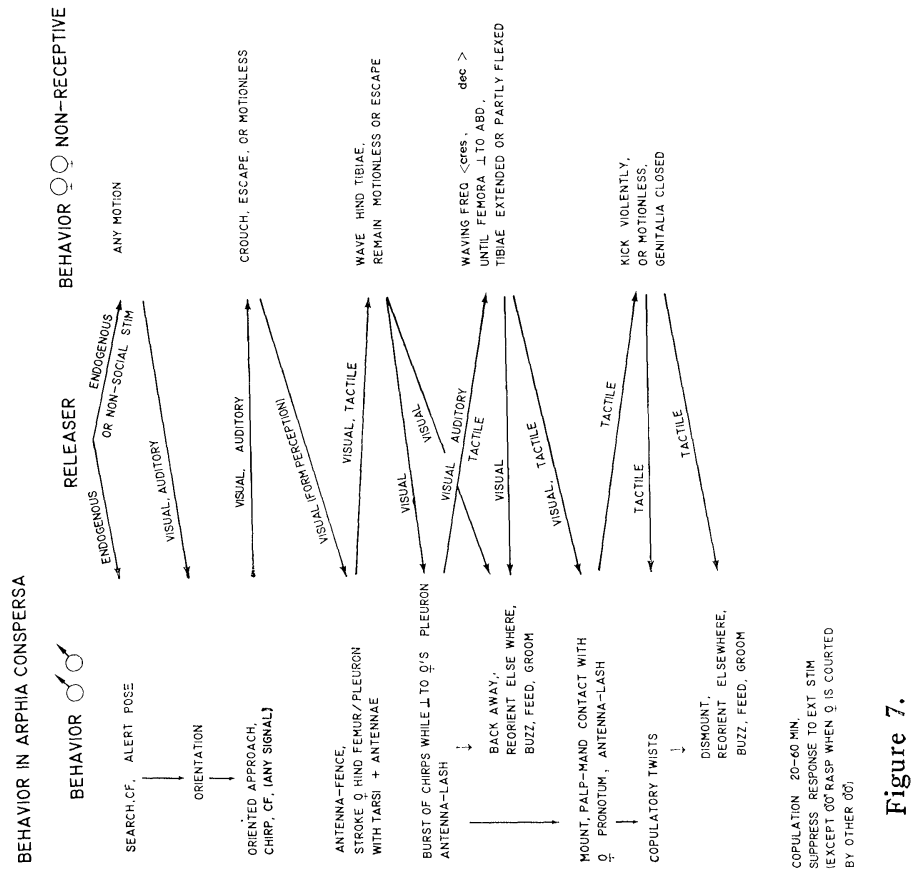

竞
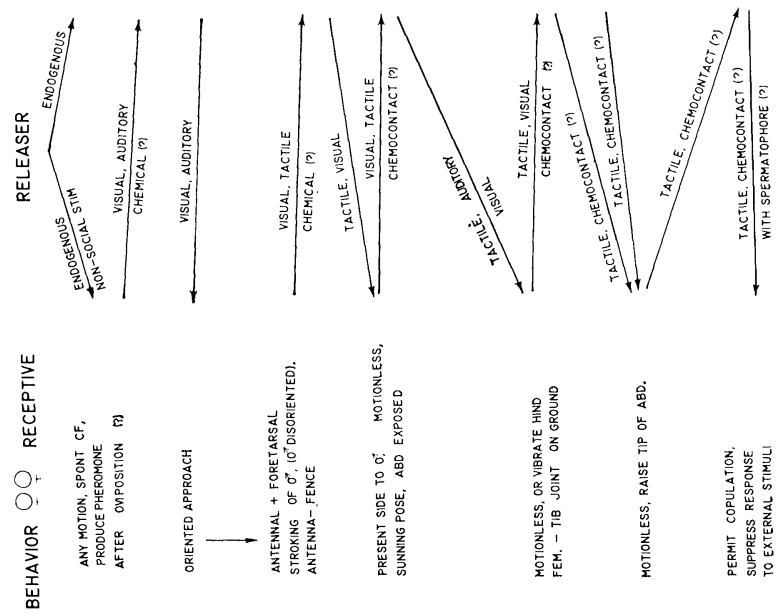

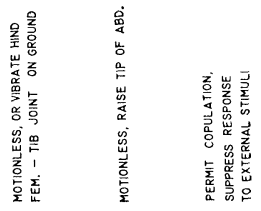


suddenly oriented to her right side and chirped four times. She turned to face him and they exchanged antennal contact. She walked past him, circled clockwise and paused with her rear toward him. He ran to her front and mounted on her head. He then turned into the proper position on the female and copulated. The pair was in copulo for 23 minutes. This male seemed disoriented at first, and probably was not in full courting condition even though the female accepted him. However, the female seemed to be in a state of high receptivity and may have been soliciting courtship herself.

After uncoupling from the male, females often accept courtship and mounting by other males, but copulation has never succeeded during our observations, probably because the genital orifice is obstructed by the spermatophore. Under such conditions they dismount after fifteen seconds or so. Males, after they have copulated, are not usually responsive to females for 15 to 20 minutes but few males have been carefully observed in this condition. Unresponsive females show their lack of receptivity by (I) keeping closed the subgenital plate with no further evidence of resistance, (2) lowering the wings over the genitalia, (3) raising the hind femora until they point forward above the head with the tibiae stretched out above the horizontal plane and slowly waving the tibiae up and down, sometimes increasing the frequency and decreasing the amplitude until the femora are vertical and tibiae flexed, (4) kicking the male off, (5) running away and (6) flying away. It is striking how effectively the tibial waving turns off the courtship. In the field ( 1963) we observed one persistent male who was kicked off vigorously by a female. He returned to court again and oriented in the premounting position at the rear of the female. But when she waved the hind tibiae, he backed off and ran in another direction, chirping about four times as he went. It is possible that this is a learned response, for we have viewed many such encounters in the laboratory among naive or previously deprived males.

\section{Male-Male Interaction}

When males meet on the ground, after crepitating toward one another or during their ground level wandering, they pause at distances up to two feet apart and orient by one facing the other in an alert pose. They then crepitate, hop, spurt-run or walk to close proximity of each other. The approach is sometimes accompanied by chirping. Usually one (A) orients perpendicular to the side of the thorax of the other $(B)$, and touches it with the antennal tips. Then (B) responds with a flutter-rasp (Fig. 9) with one or both 
legs, (A) answers and turns his body parallel to (B), either facing the same or opposite direction. They then generate flutter-rasps in alternation three or four times. After this sequence, if they are facing in opposite directions they walk in opposite directions, and, a few inches apart, pause in an alert pose for up to several minutes. They then crepitate in opposite directions, one first and the other a second later. If they face the same direction, they may walk parallel and flutter-rasp in several sequences before parting. We have observed in the field and more often in the laboratory that the members of some pairs seem to be of equal aggressive strength and both try to point toward the other's side. As a result, they circle around a common center and rasp in continuous alternation. Such bouts sometimes result in an attempt of one male to mount the other. This is followed with kicking by the mounted male and biting the dorsal carina of the pronotum by the mounting one. If a male tries to court another male, the signals of the courting male are usually turned off in mid-sequence by a responding flutter-rasp by the courted male. The courting male answers with a flutter-rasp and normal male-male interaction proceeds. However, males deprived of opportunities to court females for a few days will complete courtship and mount a vigorously rasping male. Indeed, the only response certain to be made by a male in copulo is a flutter-rasp, serving to "turn off" courtship by another male.

The flutter-rasp (Fig. 9) is produced by a rapid oscillation of the femur in contact with the tegmen. The effective sound produced is a broad-spectrum noise produced about 20 times per second whether the insect possesses one leg or two. In spectrograms of two-legged and one-legged males stridulating alternately, it is impossible to detect to which part of the sequence each belongs. Both may possess periodic double wave fronts probably produced by contact of the legs with the tegmen during both up and down stroke. Thus, as movies taken at 32 frames per second confirm, the flutter-rasp is produced by the legs moving simultaneously and in phase (if both legs are present). The burst of flutter-rasps rarely lasts more than $0.5 \mathrm{sec}$. in an active interaction and often only three or four pulses are produced, which are then answered by a similar or longer train of pulses within a tenth of a second. The frequencies are difficult to ascertain, but the fundamental tends to range between 2000 to IOOOO $\mathrm{Hz}$ or higher with overtones at intervals of 5000 or $6000 \mathrm{~Hz}$. These are the major frequencies from field recordings. The sound to the human ear is much more tonal than that of the crepitation 


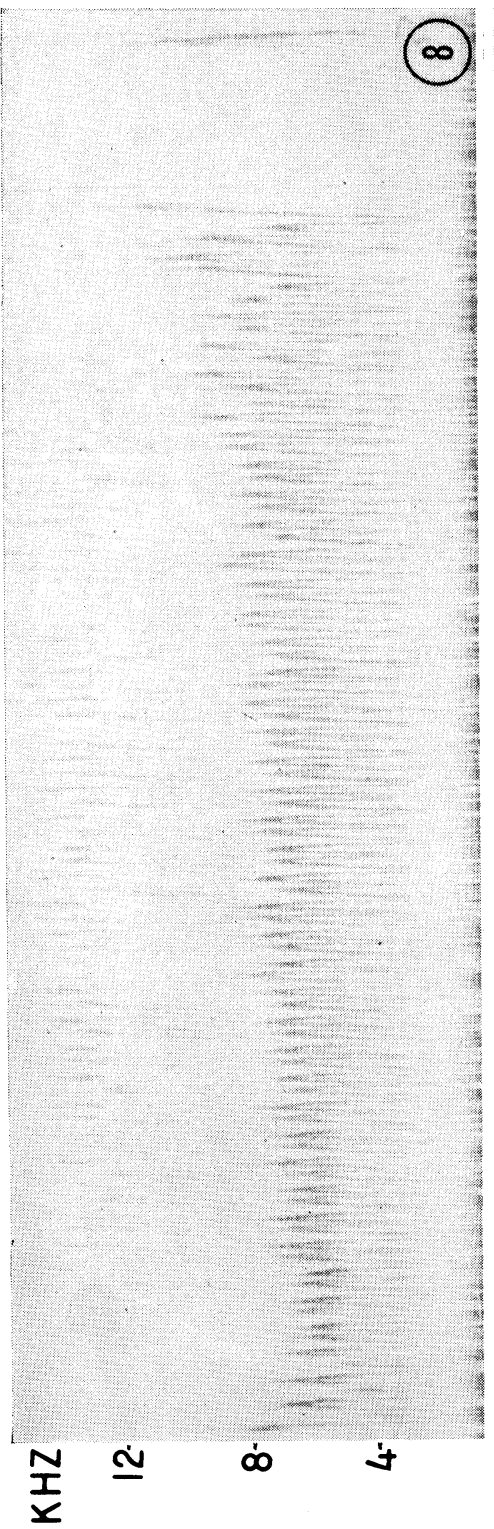

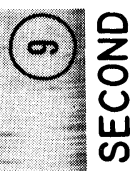

in

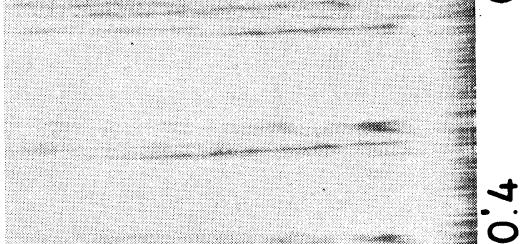

$=0$ 
but much softer, blurred, and less tonal than the chirp. The amplitude is variable, but ranges from 30 to $45 \mathrm{db}$ at four inches on the A scale of the sound level meter.

Other male signals.

A buzz (Fig. 8) and flutter-squeal (Fig. 6) by males have as yet no certain communicative function. However, they are made frequently enough and under such peculiar circumstances that they seem to be part of the normal male repertoire and their significance is an intriguing problem.

The buzz lasts I to 2 seconds with a pulse frequency of about I IO-I2O per second, and stops abruptly. The pulses are paired with a shorter time interval between each member of the pair than that between the pairs. The overall intensity measures 50 to $60 \mathrm{db}$ at 4 inches on the $\mathrm{B}$ and $\mathrm{C}$ scale, and is loudest when the insect has its side directed to the microphone. There are several major overtones above a gliding fundamental giving a rising and falling "chord" to the first pair member and only a rising one in the second. It is likely that the pairs represent some order of up and down stroke of the femora in strong contact with the tegminal pegs. We formerly thought that the buzz of Arphia males was a rare sound (Willey \& Willey, 1964), but it is frequently given in captivity by 3-4 week old males especially after the male has been refused by a female several times or is in isolation while other pairs nearby are courting. We have a tape of about 50 buzzes produced by ro males during 7 minutes, each one paired with an unresponsive female in a separate mating cage (August, r968).

So far, no female has shown any reaction to the buzz other than

Figure 8. Field recording of entire buzz with an after-stroke resembling a very brief chirp. Note the paired nature of the strokes, sharp frequency and amplitude peaks, the even double pulse rate, increase in frequency peaks and their variability, and the abrupt beginning and ending of the song. The high frequency "ghosts" peaking at 12 to $16+\mathrm{KHz}$ probably represent an artifact of the spectrograph.

Figure 9. Laboratory recording of flutter rasp between two males. The first three pulses were delivered by a normal male using both hind legs, the train of 5 double strokes was given by a one-legged male obviously contacting the tegminal file on both up and down strokes. One of the pair of strokes is identical to that one given by the two-legged male, indicating temporal precision in deployment of the two legs making that stroke. The second of the paired strokes resembles a single pulse of the buzz in its frequency peak characteristics. There is considerable variation in the time spacing of the strokes. Again, the "harmonics" are probably largely due to spectrograph artifact based on the basic pulse repetition rate of the fundamental tone. 
moving away from the sound. An anecdote from our field notes illustrates this situation. Late in the season ( 1964 ), an active male crepitated to within one foot of a female who immediately started running away from the male. She ran behind a clump of grass and lodged herself in a crevice formed by a stone so that she was hidden from the chirping male. He became "disoriented", moved a few inches in each of several directions and chirped two or three times every few seconds. Then he spurt-walked, buzzing at every pause. This behavior continued for 15 minutes and included two circuits. Each time he returned to the area, by about a foot, where he last saw the female. The female several times "peeked out" and, as the male approched the stone, backed in again. There seemed to be a regular decrease in the rate of the chirping and buzzing which finally ended when the male came to rest in an alert pose. After several minutes he crepitated away. We have observed a similar and normal ground behavior in the acridine Aeropedellus clavatus, wherein the male runs short distances over the ground, stops to buzz for several seconds, assumes a brief alert pose and then runs again.

Another peculiar aspect of the buzz is that we can "turn it on" sometimes. The reset mechanism of our Exakta camera resembles to our ears a crepitation (Fig. 3). Of ro males in the field which were subjected to this sound (produced while one of us was lying prone about I5 inches away), five ran up to within three or four inches of the lens and then turned sideways to the camera and buzzed (Fig. I).

We have heard the flutter squeal three or four times in the field. Only once was the individual which produced it positively identified. A squeal-like sound is sometimes produced by a male captured in a net or picked up by hand. In captivity, in a large flight cage, it is more frequently produced. The squeal is given when a loud crepitation by another male passes less than two feet overhead. A squeal by a captive male, with the probable cause - a crepitation immediately preceding it, is illustrated in Fig. 6. Unfortunately, the sound intensity could not be measured directly with a sound-level meter, but we infer from cross-sections of the sound made by the audiospectrograph that it is $<45 \mathrm{db}$ at 4 inches. The one reaction to the squeal was noted in the field where the overhead male in crepitation flight suddenly deviated about $60^{\circ}$ and alighted seemingly prematurely near a squealing male. The landing male chirped in typical courtship manner and was answered by an intense flutterrasp by the other male. 
Finally, there is the silent raising and lowering of the legs by both sexes, nymphs and adults, which seems related to what Otte (1968) calls "femur-raising". The femora are raised relatively slowly to the vertical position and the tibiae are extended during this time about $30^{\circ}$ to $60^{\circ}$ from the closed position. The complete motion takes about one second and may take longer. This motion is fairly constant in detail and is a warning signal to any insect approaching. In nature, the intruder usually avoids the femur-raising insect or begins a definite social reaction. The effect of the signal, then, is to advertize that the grasshopper is not an inanimate object suitable for tasting or crawling upon. First instar nymphs exhibit this behavior as soon as they emerge from the pronymph. In captive populations this motion intergrades with the intense repulsion display of non-receptive adult females mentioned under courtship. Under crowded conditions, even males may begin tibial-waving and other signs of intense disturbance, but usually the warning signal does not vary much in normal interactions.

Extraneous sounds and the use of models.

Males will respond to motions other than the normal interaction noises. The human voice commonly is ignored by grasshoppers, but broad spectrum clicks and other sounds with sharp wave fronts produce definite effects in the behavior. These effects range from sudden freezing in position to flight, to assumption of the alert pose or even orientation toward the source. A chipmunk (Eutamias sp.) called 25 feet away while one of us was watching two males interact; they oriented to the source and ran about I 2 inches toward it. Although they did not chirp, the sudden and simultaneous nature of their activity with the final pause in full alert pose, was characteristic of presocial orientation behavior. Figure 5 shows the vague resemblance of the chipmunk's alarm cry to the chirp of the courting male. The aforementioned Exakta reset buzz (Fig. 3) is another example of the ease of producing social behavior with artificial acoustic models and indicates that the acoustic and visual signals produced by the same motion are not necessarily closely linked, but rather only intensify the effect.

Males will also mount and attempt to copulate with sticks, thermometers and the rolled edges of cardboard cream cartons. However, approach sounds are seldom used to communicate with motionless objects. They seem to come upon these items by accident and proceed with the use of tactile feedback. This behavior seems to be characteristic of males between 15 and 25 days old. We are presently 
studying the diverse parameters of this behavior using visual and acoustic models.

\section{DISCUSSION}

Few thorough studies have been published concerning the behavior of oedipodine grasshoppers, whereas their close relatives, the Acridinae, have received more attention. Faber in I936 and 1953 documented the behavioral repertoire of about a dozen European oedipodines with verbal descriptions but could not present oscillographic nor audiospectrographic displays. The most extensive study to date (Otte, I968, 1969) has surveyed the social interaction of nearly Ioo North American species of oedipodines and acridines, including six species of Arphia. However, A. conspersa was not described in detail. Other workers have analysed many aspects of the biology of the plague band-wing, Locusta migratoria and several species of the acridines Chorthippus and Gomphocerus (Faber, I953; Haskell, 1962; Huber, 1963; and Perdeck, 1957).

R. Alexander ( 1967 ) lists nine functional categories of arthropod acoustical signals (other types of signals also could be so classified) as follows:

I) Disturbance and alarm (predator-repelling and conspecific alarming) signals.

2) Calling (pair-forming and aggregating) signals.

3) Aggressive (rival-separating and dominance-establishing) signals.

4) Courtship (insemination-timing and insemination-facilitating signals).

5) Courtship interruption (pair-reforming?) signals.

6) Copulatory (insemination-facilitating and pair-maintaining signals).

7) Post-copulatory or intercopulatory (pair-maintaining) signals.

8) Recognition (pair- and family-maintaining) signals (limited to subsocial and social species).

9) Food and nest site directives (limited to social species).

In Arphia conspersa only the first six categories have been observed and visual-acoustic signals are dominant in all but the sixth (copulatory) which is primarily tactile, perhaps with some contact pheromone stimuli. Fig. 7 shows a schema for courtship interaction from the flight crepitation sounds of chance encounter (onset of pair formation) through orientation, courtship chirps, to copulation. Added to these signals are the prevention of aggression signals (flutter-rasp), secondary calling signals or pair-reforming signals 
(?) (buzz), alarm signals, and perhaps a tenth category, the comfort motions such as the wing buzz, wing flick, tibiotegminal click, mandible snap, etc. which could have subtle communication significance which does not involve orientation.

At this point we should discuss the relationship of the spectrogram display relative to the probable mechanisms of sound production. According to Watkins (1967), analysis of sounds by the Kay audiospectrographs must take into account the fact that pure tones (sine waves) modulated with on-off pulses whose repetition rate is more rapid than the analysing filter can discriminate will develop a definite harmonic structure. The over and under tone intervals are predictable from the pulse tone and pulse rate; Fourier analysis can predict the sound energy at each harmonic. To a degree, the original characteristics of the sound being analysed can be deducted from the harmonic structure. Likewise, if the basic tone is a spike (a very brief pulse of energy), rapid spike repetition rates fuse into harmonic intervals equal to the repetition rate added to the preceding harmonic. The greatest energy (darkest band) will be exhibited at the fundamental frequency of the repetition rate, and will be the lowest band in the trace. The femorotegminal sounds illustrated in this paper approximate the appearance of a pulsed spike repetition quite closely and this is undoubtedly related to the impact velocity of the femoral ridge on each peg of the tegminal file. On the other hand, we have no ready hypothesis for the structural basis of the flight crepitations which sometimes resemble spikes in themselves and at other portions of the spectrogram resemble the aforementioned pulse modulation which is beyond the resolving capacity of the analysing filter. Study of this problem, using oscillography and high speed cinematography is in progress.

We shall discuss the several signals of $A$. conpsersa under their presumed functional categories as listed by R. Alexander ( 1967 ) and Otte (1968).

\section{Disturbance and alarm.}

We have found the flutter-squeal (Fig. 6) commonly enough to consider it a basic stress pattern. Its neurological basis can be guessed as the outlet for an overload which brings together under stress several independent circuits, e.g., the rapid femoral flutter mechanism of the male-male interaction and the increased medial tension on the femur as it passes over the stridulatory pegs of the tegmen. Similar stridulations are produred by many acridids during capturc. 
In addition, the wing-flick may be a secondary alarm signal when it is not a comfort movement to rearrange the folding of the hindwings. A startling display by both sexes of $A$. pseudonietana, mentioned briefly by Otte (1968) and observed by us in the western populations of that species, involves a sudden flicking open of the wings so that they point upward above the back with their outer surfaces mutually in contact. The wings sometimes stay open in this position for several seconds, with the brilliant red-orange disc of the hind-wings fully expanded. Grasshoppers which were approaching another individual will stop and back up or turn away when the latter performs this action. We have been able to cause the reaction with sudden probes or movements. We have noted also, as Otte has, that this action is effective against smaller insects, especially Diptera attempting to settle on the insect, and would be a good defence against tachinid and smaller asillid predators. However, in the six years in which we have studied the montane populations of $A$. conspersa, this behavior has never been evidenced by more than a very rapid flick with a duration of a few milliseconds. Only with the comparative data of $A$. pseudonietana does the potential communicative value of the wing flick become evident. Probably this prolonged exposure of the brightly colored wings is attractive to vertebrate predators, and only the large species can afford to use this as a communicative signal. A conspersa, for example, is so beset by avian predators in most areas that the life expectancy of whole populations is only three to four weeks (Willey \& Willey, I967). Our observations (unpublished) on $A$. conspersa in the plains of eastern Colorado indicate that these larger individuals take much longer flights, and are more conspicuous in general behavior than the montane populations. Much of the muted behavior of montane populations can be postulated as a result of extreme predator pressure.

Aggression.

The so-called "rival's song" is a common term which perhaps gives faulty perspective to the function and makeup of the maleinteraction songs. Suffice it to say that the flutter-rasp serves to turn off courtship advances by a male in, at least, two well-defined instances: I) when the courted male is alone and 2) when the courted male is part of a pair in copulo. In this way, aggression is prevented, conspicuous courtship interplays and fighting are mitigated and the insects are less obvious to predators. Indeed, the male flutter-rasp could be considered as forming also a courtship interruption signal, since the receptive female is not adversely affected by the flutter-rasp of the male in copulo and remains in a quiescent state. 


\section{Calling.}

Here there are important questions to be asked. It is obvious that the flight crepitation performs the aggregation function which is supplied by the femoro-tegminal vibratory stridulations of the male and female Acridinae (Otte, I968; Faber, I953; Alexander, I960). The crepitation by female $A$. conspersa may be equivalent to the response song of such acridines as Chorthippus females (Haskell, 1962). Although Faber ( I953) makes much of the wing buzzes of both sexes while they are are on the ground, we have never seen that this action produces any significant reaction with $A$. conspersa and it may only be a comfort movement.

During the flight, the brightly colored hind wings flash red, orange or yellow depending on the phenotype (Willey \& Willey, I967) and the flash is arresting to human eyes. The mechanism of sound production by the wing is still open to investigation. Until very recently the best guesses suggested that the sounds were produced in a manner similar to that of a fan being snapped open and shut (Haskell, I962). However, Otte ( I968) described a possible instability of the wing membrane of loud crepitators when the wing is partially expanded which "pops" into the opposite configuration and could produce the crepitation.

The presence of the femoro-tegminal solitary buzz excites interest also, since this signal seems to duplicate the function of the flight crepitation. Such sounds in the acridines are definitely implicated in the onset of pair formation and male location. Although we have never observed anything but ignoring or evasive action by females in response to the sound, the frequency of performance by solitary or recently repulsed males makes it unlikely that the buzz is completely redundant or non-functional. Otte (I968) has reported frequent buzzing ("vibratory stridulation") for $A$. sulphurea. Only once did he hear it in $A$. pseudonietana whereas we have heard it frequently and recorded it in three populations of this species. For some, but not all, populations of $A$. simplex, he reported similar buzzes, but none have been heard at all in $A$. xanthoptera and $A$. granulata. Buzzing also was recorded for $A$. conspersa, but no details were given. Further, Otte believes that the buzz is a part of the courtship, a contention which we find not entirely satisfactory, since we find that it it predominantly given under situations of solitude, refusal or loss of visual contact (as Otte also admits). It may, then, be a dual purpose sound, evolving from a call perhaps, to a courtship interruption sound (pair-reforming). Secondly, the 
opportunity for field studies to turn up this sound is remote or fortuitous at best, since the signal is most frequently performed (in $A$. conspersa) during the third and fourth week just before the general drop-off in social activity and die-off in the population due to predation. Therefore, the age of any population must be considered before comparing populations or species in this respect, and caged captives or reared populations may be necessary to turn up such sounds.

The close relationship of the Oedipodinae and the Acridinae (Rehn and Grant, I960) has significance here. Most of the Acridinae are highly specialized for emitting solitary stridulations (buzzes) as the sole, long distance male-female signalling device and usually the female is unseen. Many of the Oedipodinae, on the other hand, utilize spontaneous flight crepitation, instead, for distance communication and femoral-tegminal stridulations are less specialized and distinct interspecifically.

Courtship.

This sequence is often broken into two parts, one is the approach by the male and the other is the pre-mounting cry or Anspringlaut (Faber, 1936) produced just before the male "leaps" on the female. In $A$. conspersa the demarcation between the two songs is well marked since the approach chirp is unitary and periodically produced between or during spurts of running, but the multiple chirp (Fig. 4) is given only while the insect is standing still (near the female usually) and mounting occurs immediately thereafter unless prevented by the female's non-receptive behavior. Otte (r968) has observed the same type of demarcation in other Arphia species (and, by inference, also in $A$. conspersa) but feels that the multiple chirp is only an intensifier of the unitary sound as the male nears the female.

We are amassing data on males of known adult age in the field and in caged populations. It is evident so far that any or all of the acoustical signals by the male can be omitted even in successful courtships, and mounting of receptive females can be very casual especially among older individuals. Very little is known about the signals of female receptivity, and the observed sexual presentation by the female may only be a function of propinquity. Thus far, no vestige of stridulation has been observed in females of $A$. conspersa and has rarely been reported for any other species of oedipodine. This is despite the fact that many acridine and oedipodine females (including $A$. conspersa) have a well-developed stridulatory appra- 
tus (Rehn \& Grant, I960, and this present paper). Indeed, R. Alexander ( I960) reported that he had recorded the female response song in Chortophaga viridifasciata, an oedipodine. It is possible that virgin females in many species signal the courting males if they are at a distance or if the view of the male is obstructed. However, the probable redundancy of crepitation and response stridulation may be contributing to a selection against the weaker signal. The lack of consistent data on virgin, receptive females plus data on individual males of known age makes the courtship interaction of most oedipodines an unclear picture at best.

\section{CONCLUSIONS}

Social interaction in Arphia conspersa can be divided for convenience into two separate systems of communication involving specific methods of signaling: I ) communication at a distance and 2) communication during physical contact. In these grasshoppers, signaling from a distance involves visual and acoustic modalities. Signaling during contact is mainly tactile. Some chemosensory input generated by the receptive female may be present but such an explanation is not necessary for any of the observed signal-response systems.

Signals at a distance include sounds emitted by the wings under certain circumstances during flight, sounds produced by movements of the hind femora over the tegmina, and soundless but specialized movements of the hind legs during specific interaction sequences. Other sounds are emitted occasionally, such as mandible-clicking, wingsnapping, ground-scraping and -tapping, but we have never observed any evidence of meaningful reaction by other grasshoppers except avoidance reaction in the case of some wing-snapping. Most of those motions which seem to have communicative function combine a flash of bright color with a sound produced by the same motion. We are investigating the relative importance of the visual and auditory portions of the signal and have some evidence that the sound and color are intensifiers and modifiers in the several combinations such as the rasp, buzz, chirp and squeal. The resulting visual flicker plus the buzzing sound should be very attention-getting to grasshoppers in which auditory flicker fusion probably doesn't occur until pulse rate frequencies reach the order of 200/second (Haskell, I96I) and visual flicker fusion may be more than 50/second (Dethier, I964). However, the question of flicker perception is still an open matter and grasshoppers may have even higher rates of flicker resolution (Dethier, I964). 
It is interesting, then, how visual-acoustical signals have diversified within this species. In $A$. conspersa, the basic single-pulsed sound is similar in the chirp, rasp, buzz, squeal. Each of these signals differs primarily from the others in pulse duration, intensity, and pulse rate frequency. The chirp is intense, variably spaced, multiple and with a high pulse rate frequency. The rasp is intermediate in pulse rate frequency and of lower amplitude. The squeal is a rapidly delivered short train of chirps, with a high degree of frequency variation. It is of further significance that the unitary chirp, precopulatory burst of chirps, flutter-rasp, flight crepitation, and buzz signals differ in pulse rate frequency in an ascending scale of I, IO, 2O, 45, and $\mathrm{IOO} /$ second respectively, which indirectly indicates a Weber-Fechnerlike discrimination of pulse rate frequency. If one invokes an ascending scale of specific action potential (ethologists' SAP) which is excited by this series of frequencies to produce specific behavioral patterns, then such a relationship between perception and specific choice of behavior pattern can be postulated which could be independent of the intensity of the specific stimulus. Differences in intensity of each stimulus could in turn result in complex scototaxis and phonotaxis in a manner similar to that shown in Ephippiger spp. (Dumortier, I963). We are currently studying this problem in respect to the male-male interactions in several species of Arphia.

\section{ACKNOWLEDGEMENTS}

We are grateful for the aid of David Werner, Ruth Lewert, Allen Berlind, Gerald Mussgnug, Joyce Redemske, Melvin Shemluck, and Marianne Niedzlek, our assistants and students for at least one of the years of study. We thank Dr. Walter Roberts, Director of the National Center for Atmospheric Research and Dr. James Deardorff for enabling us to study the Table Mesa population during May and June of 1964 . We also are grateful for the aid and encouragement of Professor Robert Enders, Director of the Rocky Mountain Biological Laboratories during most of the period of this research, and Professor John Corliss, Head of the Department of Biological Sciences, University of Illinois at Chicago Circle. We appreciate the helpful suggestions and encouragement of Dr. Richard D. Alexander, University of Michigan, who made, several years ago, sonograms of signals we recorded very early in the study.

Arphia conspersa, an oedipodine grasshopper, is widely distributed 
in western North America. The nymphs overwinter and emerge as adults soon after the snows melt. The active breeding season above 8,ooo feet elevation near Gunnison, Colorado, is short and isolated temporally from that of other species which overwinter only in the egg stage.

Social communication includes silent motions of the hind legs by both sexes, as well as various frictional sounds which are produced only by the male which passes the femora over a specialized file on the tegman. Each of these patterns of movement delivers a visual and acoustic flicker stimulus which is distinct in pulse rate frequency (PRF) from all the other signals. Silent single flicks of the hind femora disclose the bright yellow (in males) or brownish yellow (in females) abdomen and serve as non-specific advertisement of presence. The sounds produced by unitary or multiple leg movements can be single chirps (courtship approach), multiple chirps (PRF up to 5/O.3 sec., probably a pre-mounting song), futter-rasp ( $\mathrm{PRF}=20$ single or double pulses/sec., prevention of aggression among males), and buzz (PRF =IIO-I20/sec., after repulsion by the female, after losing track of the female, or after hearing another courtship sequence). A squeal is produced in response to severe disturbance, such as capture, injury, loud multiple-pulsed sounds, etc. The brightly colored wings alone also produce pulsed sounds $(\mathrm{PRF}=45-5 \mathrm{O} / \mathrm{sec}$., crepitations) during spontaneous flights by males and sometimes females.

Females have not yet been observed to stridulate, though they have a normal stridulatory apparatus. They reject courtship in several ways, ranging from merely closing the subgenital plate to a threat display which involves raising the hind femora past the vertical position and waving the tibiae in a slow and deliberate manner. Acceptance of the male ordinarily is passive, but active solicitation has been observed.

This wealth of definitive signals and responses makes study of species in this genus important for communication research and the evolution of communication systems in insects.

PROTOCOL (Recording and Missilyzer transfer data) ${ }^{4}$

Fig. 2. Crepitation $=\mathrm{AKG}$ microphone with parabola, distance 3 feet, Nagra input $-20 \mathrm{db}, 15 \mathrm{ips}$, sun thermometer $40^{\circ} \mathrm{C}$, Gothic about 9600 feet; Missilyzer input VU $=+1 /+2$, output VU $-6 /-5$, ML 7.5 .

Fig. 3. Clicks produced by an Exacta camera reset mechanism.

${ }^{4}$ All recordings were at 15 ips, patterns normal, displays equivalent to normal speed ( $\mathrm{HH}$ input and output), $i p s=$ inches per second, analysing filter bandwidth for all displays $=600 \mathrm{~Hz}$. 
Fig. 4. Chirp - Sennheiser 804 microphone, 3-4 in., $0 \mathrm{db}, 15$ ips, $37^{\circ}$ incandescent lighting, grasshopper age 4 weeks from Black Mesa, recorded at Gothic at 9500 feet; Missilyzer VU in $-1 / 0$, VU out $-6.5 /-.5$, ML 7.5.

Fig. 5. Alarm cry of a chipmunk (Eutamias sp.) - AKG microphone with parabola, 20 feet, $-20 \mathrm{db}, 15$ ips, about $25^{\circ} \mathrm{C}$ (6:00 MDT), recorded at Gothic, 9700 feet; Missilyzer VU in $+2 / 3$, VU out $-10 /-7$, ML 8.0.

Fig. 6. Crepitation and squeal-AKG microphone without parabola, 4-8 in, $-10 \mathrm{db}, 15 \mathrm{ips}, 37^{\circ}$ Sun, Gothic 9500 feet; Missilyser $V U$ in $+2 /+3$, VU out $-10 / 7$, ML 8.0, Spectrogram repeated at VU -10 five times to emphasize squeal over background (no decrease in resolution was observable).

Fig. 8. Buzz - AKG microphone with parabola, 3 feet, $-20 \mathrm{db}, 15 \mathrm{ips}$, $40^{\circ} \mathrm{C}$, Gothic at 9600 feet; Missilyzer VU in $+2 /+3$, VU out $-.5 / 0$, ML 7.5.

Fig. 9. Flutter-rasp - Sennheiser 804 microphone, 4 in. 0 db, 15 ips, $37^{\circ} \mathrm{C}$ incandescent lighting, grasshopper age about 4 weeks from Black Mesa, recorded at Gothic at 9500 feet; Missilyzer VU in $+1.5 /+2.5$, VU out $-6.5 /-5.5$, ML 7.5 .

Alexander, R. D.

\section{Literature Cited}

1960. Sound communication in Orthoptera and Cicadidae. In: Lanyon, W. E. and W. N. Tavolga (Editors), Animal Sounds and Communication. (Washington, D.C.: Amer. Inst. Biol. Sciences), pp. 38-92.

1967. Acoustical communication in arthropods. Ann. Rev. Entomol., 12: 495-526.

DETHIER, V.

1963. The Physiology of Insect Senses (New York: Wiley), 266 pp. DUMORTIER, B.

1963. Ethological and physiological study of sound emissions in Arthropoda. In: Busnel, R.- G. (Editor), Acoustic Behaviour of Animals (New York: Elsevier), pp. 583-654.

FABER, A.

1936. Die Laut- und Bewegungsäusserungen der Oedipodinen. Zeitschr. wissensch. Zool., 149: 1-85.

1953. Laut- und Gebärdensprache bei Insekten. I, Orthoptera (Geradflügler) (Stuttgart: Mitt. Staatl. Mus. Naturk.), 198 pp.

Halliburton, W. and G. Alexander

1964. Effect of photoperiod on molting of Chortophaga viridifasciata (De Geer) (Orthoptera: Acrididae). Entom. News, 75: 133-137.

HASKELL, P.

1961. Insect Sounds (Chicago: Quadrangle), $189 \mathrm{pp.}$

HighKNAM, K. AND O. Lusis

1962. The influence of mature males on the neurosecretory control of ovarian development in the desert locust. Quart. Jour. Microsc. Science, 103: 73-83. 
Huber, F.

1963. The role of the central nervous system in Orthoptera during the co-ordination and control of stridulation. In: Busnel, R.-G. (Editor), Acoustic Behaviour of Animals (New York: Elsevier), pp. $440-488$.

OTTE, D.

1968. A comparative study of communication in grasshoppers. University of Michigan, Ph.D. Thesis (Ann Arbor, Michigan: University Microfilms, \#68-13,374).

1969. A comparative study of communication in grasshoppers. Misc. Publ., Mus. Zool., Univ. Michigan, In Press.

Perdeck, A.

1957. The isolating value of specific song patterns in two sibling species of grasshoppers (Chorthippus brunneus Thunb. and C. biguttulus L.). Behaviour, 12: 1-75.

Peterson, A and E. Gross, Jr.

1963. Handbook of Noise Measurement (West Concord, Massachusetts: General Radio Co.), 250 pp.

Rehn, J. and H. Grant

1960. A new concept involving the subfamily Acridinae (Orthoptera: Acridoidea). Trans. Amer. Entom. Soc., 86: 173-185.

WatKINS, W.

1967. The harmonic interval - fact or artifact in spectral analysis of pulse trains. In: Tavolga, W. (Editor), Marine Bio-Acoustics, 2 (New York: Pergamon), pp. 1-43.

WiLley, R. B. AND R. L. WILley

1964. Social interaction among adults of the grasshopper, Arphia conspersa. Amer. Zool., 4(3): Abstr. \#163.

1967. Barriers to gene flow in natural populations of grasshoppers. I. The Black Canyon of the Gunnison River and Arphia conspersa. Psyche 74: 42-57. 

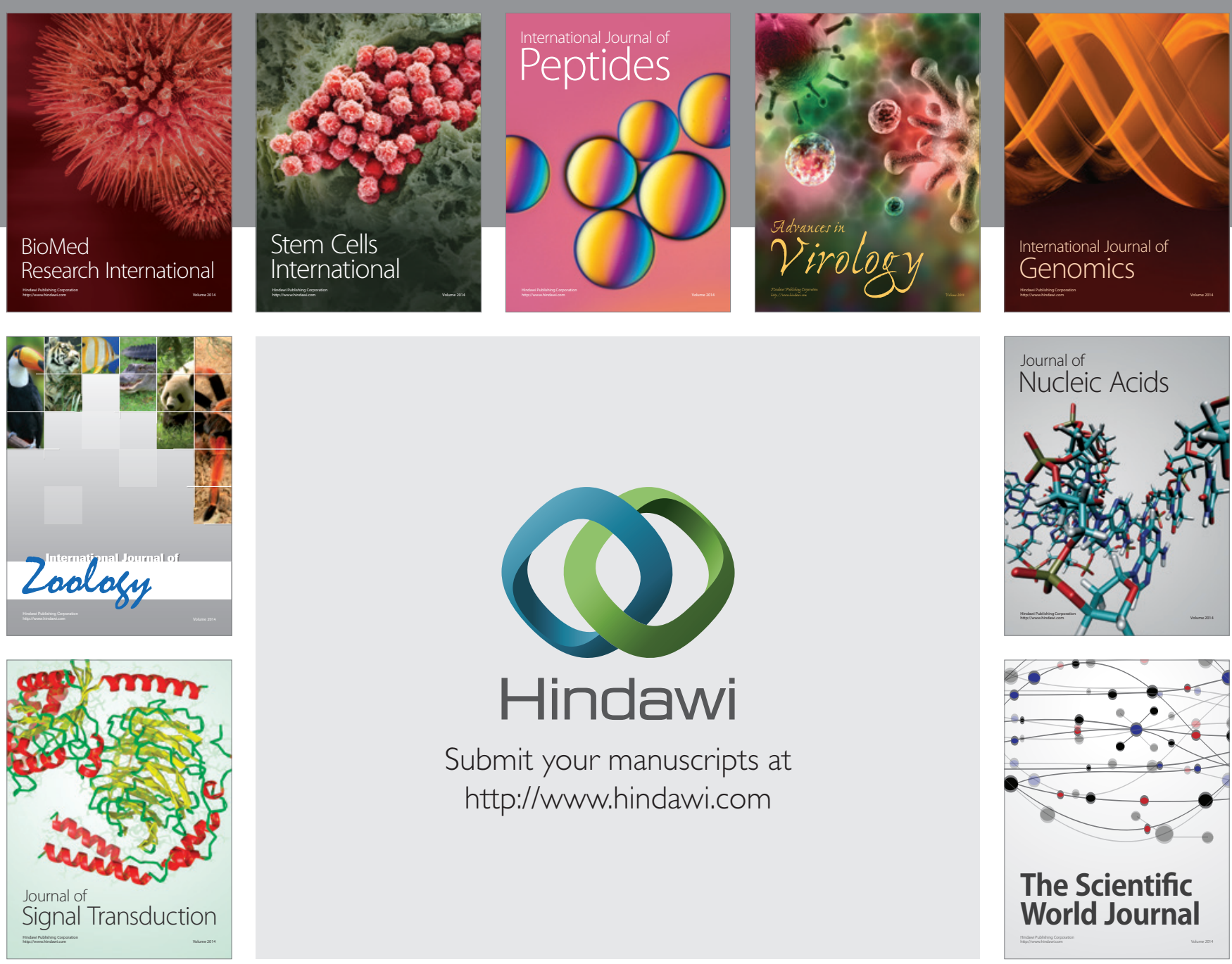

Submit your manuscripts at

http://www.hindawi.com
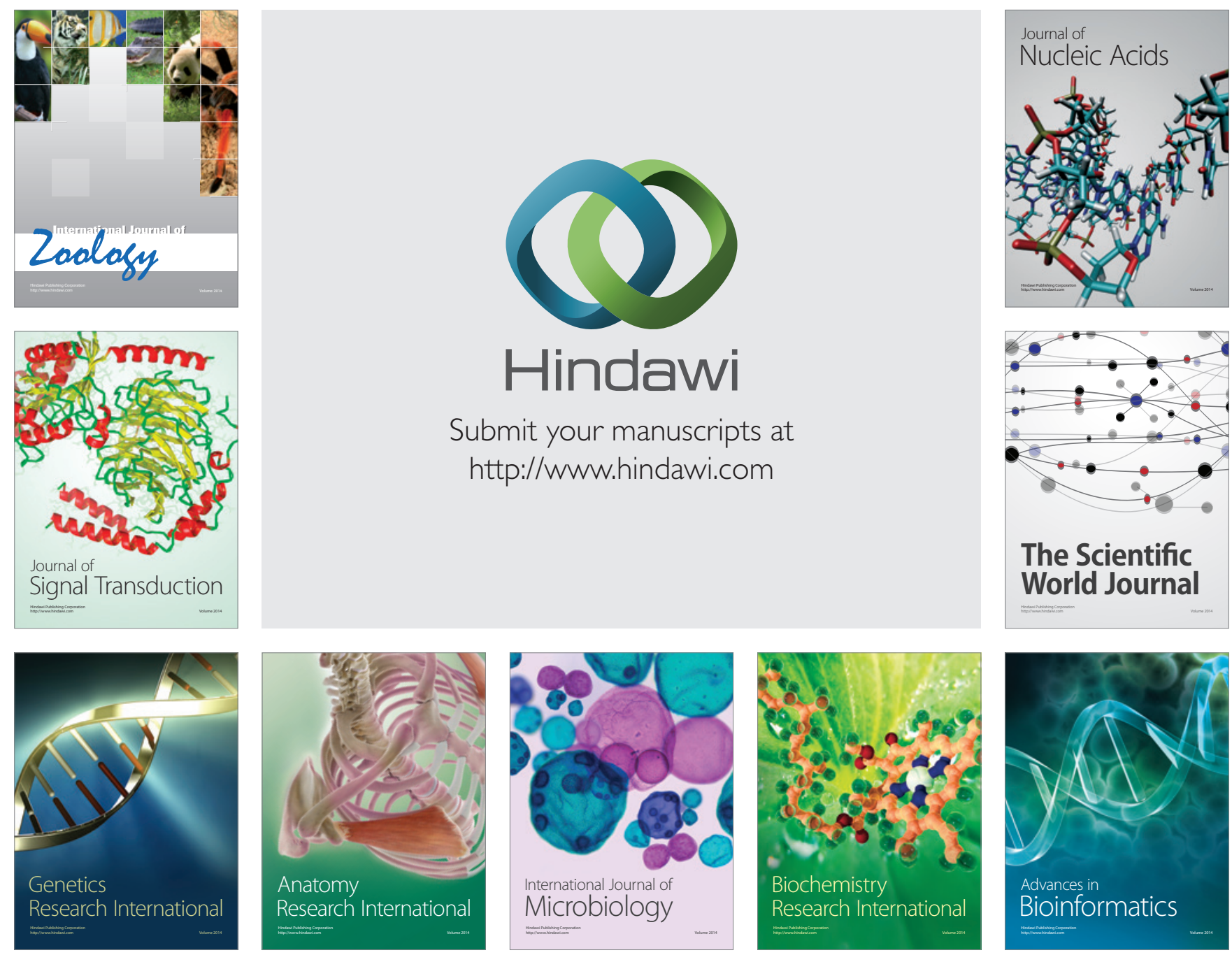

The Scientific World Journal
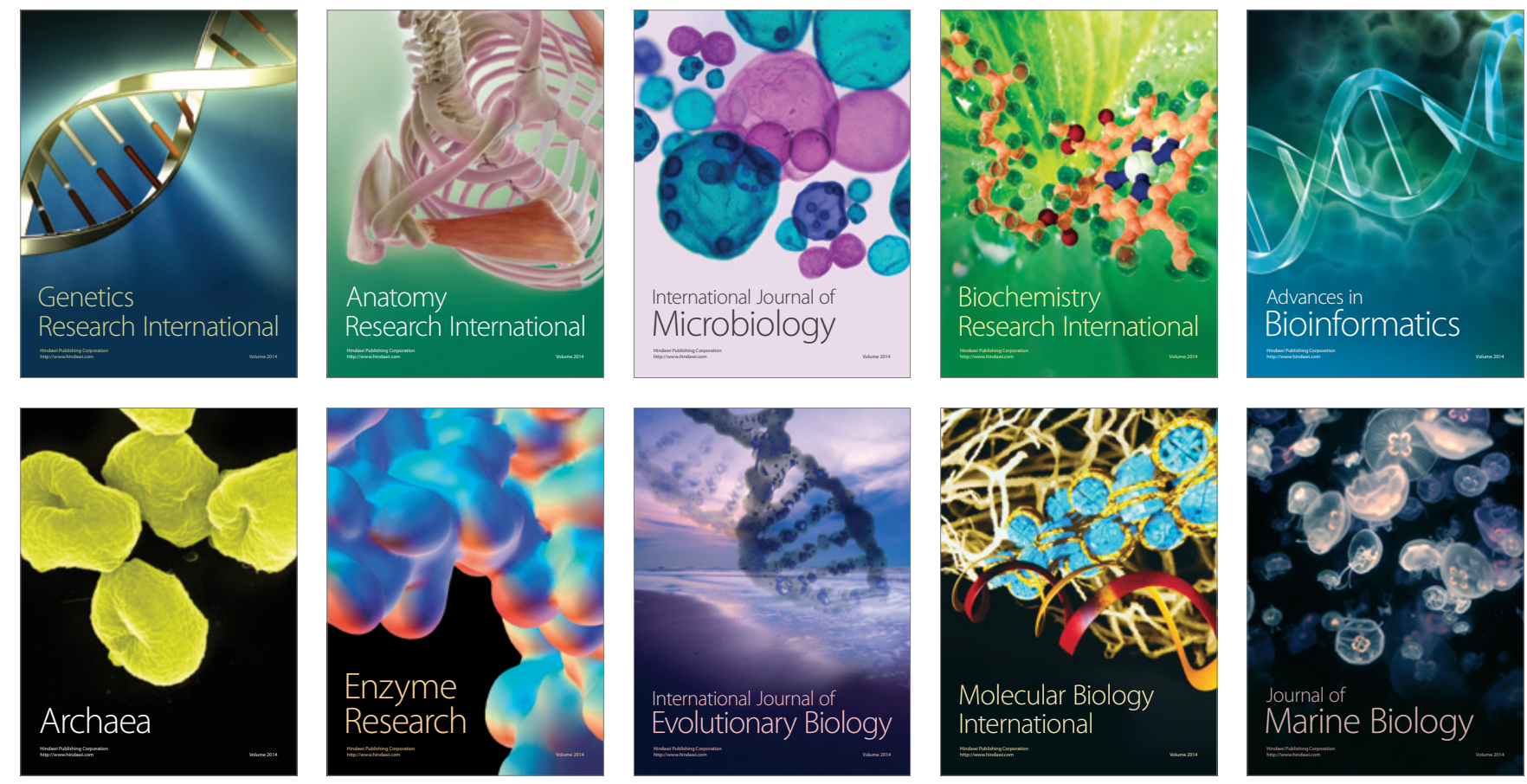